Tomás Ariztía, editor. Produciendo lo social. Usos de las ciencias sociales en el Chile reciente. Santiago: Ediciones Universidad Diego Portales, 2012.

\title{
SOCIOLOGÍA DE LA SOCIOLOGÍA
}

\author{
José Joaquín Brunner \\ Universidad Diego Portales
}

\begin{abstract}
A
propósito del libro Produciendo lo social. Usos de las ciencias sociales en el Chile reciente, publicado por un grupo de autores y editado por Tomás Ariztía ${ }^{1}$, es posible iniciar una reflexión sobre el rol que estas disciplinas desempeñan en la sociedad. El libro mismo versa sobre múltiples tópicos interconectados: el poder de las ideas, el rol de los tecnócratas en la política, los economistas como intelectuales independientes o funcionarios, la función performativa del conocimiento económico en la construcción del mercado de seguros de salud, el papel
\end{abstract}

José Johquín Brunner. Ph. D. en sociología por la Universidad de Leiden, Países Bajos. Profesor titular de la Universidad Diego Portales, donde dirige la Cátedra UNESCO de Estudios Comparados de Educación Superior y el Programa de Doctorado en Sistemas, Políticas y Gestión de la Educación Superior ofrecido conjuntamente por las Universidades Diego Portales y de Leiden. Miembro de número de la Academia de Ciencias Sociales, Políticas y Morales del Instituto de Chile. Dirección electrónica: josejoaquin.brunner@ cpce.com.

${ }^{1}$ Los autores de los diez estudios incluidos en el volumen son Tomás Ariztía, Oriana Bernasconi, Manuel Gárate, Alfredo Joignant, John Markoff, Verónica Montecino, José Ossandón, Alejandro Pelfini, Claudio Ramos, Christian Retamal, Patricio Silva, Manuel Tironi (Ariztía, editor, 2012). 
de los think tanks y tecnócratas en el proceso de recuperación de la democracia, la vocación pública de la sociología chilena durante los años 90, la filosofía como disciplina y su institucionalización universitaria, las nuevas formas de relación entre elites y masas en América Latina, la construcción social de experticia en situaciones urbanas controversiales, y la producción de una razón de Estado por parte de los technopols políticos de alto perfil técnico- al comienzo de la transición. ¿Cuál es la unidad o coherencia de textos aparentemente tan disímiles? ¿Qué reúne en un solo volumen a asuntos tan diversos como los informes bianuales del PNUD sobre el estado de la nación; el papel de las organizaciones ciudadanas en la planificación urbana; la creación de mercados; el trabajo de los especialistas en la manipulación de lenguajes, conocimientos y símbolos, y la circulación de ideas, minutas y actos de habla?

\section{Campos y performatividad}

La respuesta se encuentra en Bourdieu, en sus análisis de campos o espacios sociales, en particular, el campo académico, el campo intelectual y el campo del poder simbólico, que son categorías centrales de su obra (Bourdieu, 2000; Bourdieu y Wacquant, 2008). Recuérdese que los campos bourdianos deben entenderse como configuraciones o redes de posiciones que delimitan un espacio organizado jerárquicamente en torno al volumen y tipo de capitales que comandan sus ocupantes: agentes e instituciones. Así, por ejemplo, Bourdieu habla de un campo intelectual "para designar la matriz de instituciones, organizaciones y mercados en la cual los productores simbólicos — como artistas, escritores y académicos - compiten por el capital simbólico. Incluso la ciencia — que se proclama a sí misma como la más alta expresión de la objetividad - es producida dentro del marco de un campo social" (Swartz, 1997:117-118).

Pues bien, simplificando al máximo puede decirse que uno de los hilos argumentales que entreteje al conjunto de textos reunidos en este volumen postula que la producción del campo de las ciencias sociales chilenas y sus usos durante los últimos veinte años han contribuido a definir y a legitimar nombres, clasificaciones y categoría a través de los cuales percibimos, interpretamos y actuamos el mundo social dentro del cual nos desenvolvemos. En diversas partes de su obra el propio Bourdieu insiste en esta idea: que los intelectuales, los científicos sociales, 
los literatos, los expertos en conocimientos esotéricos, contribuyen a crear, denominar, categorizar y sostener instituciones, grupos, identidades; en suma, realidades sociales. Los autores de Produciendo lo Social... se sitúan de lleno dentro de esta misma perspectiva. Ofrecen estudios de casos y desarrollan enfoques conceptuales sobre diversas modalidades de producción de objetos sociales: mercados de riesgo, cartas de navegación, descripciones y autoentendimiento de la sociedad, legitimaciones y deslegitimaciones de diversos arreglos institucionales, estados de opinión, configuración de políticas públicas, relaciones de poder, etcétera.

La pregunta que cabe hacer es si más allá de los límites de este libro y sus ilustraciones técnicas existe en nuestra sociedad un uso suficientemente amplio e intenso de las ciencias sociales como para justificar una empresa de análisis de esta envergadura. Sin dudarlo, respondo que sí. Efectivamente, estamos rodeados de lo que varios autores de este volumen llaman la performatividad de las ciencias sociales, que conforme al uso de Judith Butler significa algo así como que las prácticas discursivas propias de estas disciplinas contribuyen a constituir o producir la realidad que nombran. Dice ella: "Dentro de la teoría de los actos de habla, un performativo es aquella práctica discursiva que pone en acto o produce lo que nombra" (Butler, 1993) ${ }^{2}$. Otra manera de expresar esta idea es que nuestras percepciones, las convenciones en que participamos, las instituciones que regulan nuestro comportamiento, las categorías cognitivas que usamos, incluso la identidad y estilos que nos distinguen carecen de algo así como un fondo o núcleo esencial. Por el contrario, son construcciones ideológicas en buena medida. Poseen una historia que las antecede y que ponemos continuamente en acto, que es la forma, precisamente, a través de la cual existen. Algo no muy distinto debió pensar Marx cuando escribió en el 18 Brumario: "Los hombres hacen su propia historia, pero no la hacen a su libre arbitrio, bajo circunstancias elegidas por ellos mismos, sino bajo aquellas circunstancias con que se encuentran directamente, que existen y les han sido legadas por el pasado".

2 Tomo las citas de Dino J. Butler de Felluga, "Modules on Butler: On Performativity", Introductory Guide to Critical Theory, Purdue University. Disponible en: http://www.purdue.edu/guidetotheory/genderandsex/modules/ butlerperformativity.html. Visitado 2.11.2012. 
Cito a Butler de nuevo para ver cómo la teoría de la performatividad reelabora este pensamiento: "El acto que uno realiza, el acto que uno escenifica es, en un sentido, un acto que ha venido desarrollándose antes de que uno entre en escena. Por ejemplo, el género es un acto que ha sido ensayado, tanto como el guion que sobrevive a los actores particulares que lo usan, pero que requiere actores individuales para ser actualizado y reproducido una vez más" (Butler, 1990).

Dentro de la latitud que ofrece esta metáfora sobre el poder de las prácticas discursivas, y ateniéndonos únicamente al uso de las ciencias sociales, es posible afirmar que el golpe militar en Chile se inició con un recurso a la sociología de Weber sobre la legitimidad o falta de legitimidad del ordenamiento político; continuó con un despliegue de sus propias bases ideológicas contenidas en El ladrillo, producto de un puñado de economistas inspirados en Chicago, y concluyó con un plebiscito donde la contribución performativa de la publicidad apoyada en datos de las ciencias sociales, especialmente sociología y psicología social - fue decisiva para el triunfo del NO, al punto de convertirse en un producto cinematográfico veinte años después. También la Transición (con mayúscula) — y los encendidos debates en torno de ella - pueden interpretarse como un ejercicio discursivo nacido dentro del campo de las ciencias sociales y como una lucha por nombrar y estabilizar los significados de la transformación experimentada por el campo del poder simbólico en el período de la posdictadura. El propio nombre (con mayúscula) de dicho proceso, así como sus contenidos y efectos, han sido elaborados a la luz de encuestas y focus groups, dentro de redes semánticas y con categorías de la ciencia política, la sociología y la economía; y así también iluminados a partir de influencias intelectuales e ideológicas ligadas a escuelas de pensamiento, autores del campo de las ciencias sociales y a un flujo ininterrumpido de polémicas en el ámbito académico-político.

\section{La socialización de las ciencias sociales}

Al momento presente, la incidencia de las prácticas discursivas de las ciencias sociales en la esfera pública es notable. Anteriormente esto ocurría solo con la economía y, antes aun, con el derecho y la historiografía. En cambio hoy vivimos en un mundo donde también las ciencias sociales no-económicas — como sociología, ciencia po- 
lítica, comunicaciones, antropología en alguna medida, e híbridos como economía política, ciencias de la educación, public policy, teoría de las organizaciones y sistemas, etcétera - tienen una fuerte presencia en los medios de comunicación y en la opinión pública. Ejemplos abundan: se discute sobre la felicidad de las personas no en base a la poesía y la filosofía sino a indicadores proporcionados por la "aritmética social". Los debates relativos a los malestares de la modernidad y "el modelo" vienen acompañándonos desde los año 1997-1998 y han pasado a ser la "madre de todas las batallas" en el campo ideológico. El lenguaje cotidiano está plagado de términos disciplinarios como capital social, competitividad, movimientos sociales, burocracias y fallas de mercado. Incluso la política se piensa, comunica y actúa —en el foro provisto por los medios de comunicación e internet y en la conciencia de los actores - a través de conceptos proporcionados por la investigación social: legitimidad de las instituciones, crisis de representatividad, sistema binominal, transparencia, narrativas o relatos, etcétera.

La pregunta entonces es cómo se ejerce la performatividad de las ciencias sociales en el campo del poder simbólico. Aquí el libro que comentamos está lleno de interesantes hallazgos. Sin ánimo exhaustivo, y $\sin$ miedo a repetirnos, uno encuentra allí referencias a variadas operaciones performativas en distintos ámbitos y niveles:

- La operación del gran relato (estilo transición, modernización, profundización democrática, cohesión social, globalización, etcétera) y de las pequeñas narrativas locales, coyunturales, supuesto ideológico del sentido común.

- La autocomprensión social construida a través de términos clave generados por las ciencias sociales y repetidos incansablemente en la esfera de la comunicación social que nombran la transición, el malestar, los modelos, el mercado, el capital social, la confianza, la inseguridad, la estabilidad, etcétera.

- La conexión de las ciencias sociales con los media y el rol performativo de las y los expertos que enmarcan e interpretan los procesos y situaciones en clave discursiva esotérica; por ejemplo en la televisión, donde ya no es raro encontrar diariamente a sociólogos, politólogos, encuestólogos e investigadores de distintas disciplinas (relaciones internacionales, salud pública, urbanismo, criminología, psicología laboral, expertos electorales o financie- 
ros) ofreciendo interpretaciones autoritativas en nombre de su disciplina, especialidad, experticia o, en lo mínimo, de sus credenciales educacionales.

- Los nuevos roles de los cientistas sociales como agentes directos del poder en la cúspide del aparato del Estado (ministros de hacienda, por ejemplo); como technopols, tecnócratas y tecnoburócratas; como analistas del primer piso en el Ministerio Secretaría General de la Presidencia o del segundo piso en calidad de asesores performativos del Príncipe.

- El papel crucial de los economistas (doctores de Chicago, Harvard, MIT. Berkeley) a cargo de las palancas presupuestarias del Estado mediante las cuales, en la práctica, se debe canalizar y poner límite a los deseos de las masas, a la presión no discursiva de los poderes fácticos y a las reivindicaciones de los intermediarios del poder político.

El rol que comienzan a jugar las ciencias sociales, el conocimiento experto y el despliegue de discursos autoritativos y legitimatorios en relación con los movimientos sociales y las organizaciones ciudadanas, produciendo - aparentemente al menos - una ruptura del secular vínculo que ha existido entre el conocimiento y las elites del poder para desplazarlo - en parte- hacia la sociedad civil, agentes alternativos, organismos nogubernamentales y contrapoderes.

La función desempeñada en los procesos de transferencia del conocimiento desde el campo académico al de la política y la acción social por ciertos dispositivos, tecnologías y microoperaciones, los cuales, a fin de cuenta, son los vehículos de la performatividad: minutas, citas, comisiones ad hoc, informes, memos, estadísticas, regresiones, lenguajes esotéricos, indicadores, encuestas, grupos focales, seminarios, think tanks, documentos de trabajo, artículos de journals, etcétera. Confieso que para mí, personalmente, este último aspecto de los estudios resulta uno de los más novedosos y de mayor interés sociológico. Muestra, por así decir, las redes subterráneas del poder de la performatividad y la performatividad del poder; su cara oculta, sus modos microfísicos de actuación como los llamaba Foucault (1992). En suma, revela el entramado material de las operaciones de cono- 
cimiento y la caja de herramientas (otra fórmula foucaultiana ${ }^{3}$ ) que se utiliza en el campo de luchas simbólicas.

\section{Efectos imprevistos y perversos}

Las operaciones performativas así como el uso de las ciencias sociales suelen provocar efectos no previstos, incluso perversos en algunos casos. Reseño a continuación algunos que ilustran este aserto:

- La combinación entre encuestas intensivamente aplicadas, no siempre confiables ni técnicamente acabadas, y media que usan sus resultados sin recato ni resguardos, genera un universo discursivo que se superpone al de la percepción común y de las construcciones ideológicas. Un universo de promedios, de segmentaciones categoriales, de los no sabe/no responde, de respuestas reflejas y descontextualizadas. Un universo a ratos fantasmagórico, plano, desconfiado, masivamente individualizado, anónimo, "municipal y espeso", sobre el cual se monta en seguida un flujo de interpretaciones, falsas iluminaciones, rearreglos de la realidad. Ganan las y los encuestólogos; los medios de comunicación que ayudan a producir estos actos masivos de habla (voz del pueblo, voz de dios) y después crean, difunden y comentan el eco de dicha voz; y los analistas especializados en proporcionar claves para comprender las realidades encuestadas. Pierden los políticos que previamente monopolizaban la interpretación del sentir de las masas y entendían su tarea como un acto de conducción; los investigadores académicos que utilizan tecnologías más lentas y pesadas de interpretación y análisis, y la sociedad cuya reflexividad se ve así enajenada y sustituida por una aparente objetivación cuantitativa de la conciencia colectiva.

- La política, qué duda cabe, al tecnificarse y pasar a ser parte (cuando no un instrumento) de los grupos que controlan el conocimiento más sofisticado y valioso, queda atrapada entre

3 "Una teoría es exactamente como una caja de herramientas. [...] Es preciso que sirva, que funcione. Y no para uno mismo. Si no hay personas para utilizarla, comenzando por el teórico mismo, que deja entonces de ser teórico, es que no vale nada, o que el momento no llegó aún. No se vuelve sobre una teoría, se hacen otras, hay otras a hacer." (Así se expresa G. Deleuze en conversación con Foucault, en Foucault, 1992:82). 
la presión de los expertos (technopols, tecnoburócratas, clero intelectual y asesores del Príncipe) y la presión de las masas, situación a la que se agrega la capacidad que contemporáneamente detentan los medios de comunicación para actuar —a través de la tecnología de los escándalos, según ha mostrado Thompson (2001) - como un elemento corrosivo, disolvente, sobre las elites que disputan las posiciones de mando en el campo político democrático.

- En general, la relación entre política y conocimiento está cambiando, tal como han cambiado las bases de poder de los distintos grupos intelectuales en la que suele llamarse una sociedad de profesionales (Perkins, 1990) o expertos (Turner, 2003). Surgen nuevos grupos y campos de lucha en torno al control del conocimiento; otros se deprecian en el mercado simbólico. Por ejemplo, parte de la crisis de los partidos puede atribuirse a la separación (y enfrentamiento a veces) entre technopols y militantes. Asimismo, cabe preguntarse si la pérdida de poder del Estado $-\mathrm{y}$ de su prestigio en el campo simbólico- no se debe al progresivo debilitamiento de su monopolio sobre el conocimiento, tradicionalmente depositado en burocracias de tipo prusiano y en los segmentos meritocráticos que las alimentan.

Sociedades de conocimiento distribuido, en cambio, adquieren mayores niveles de autonomía frente al Estado; al lado de la esfera del mercado como sistema relativamente independiente de la política, se agrega ahora la esfera de las instituciones y redes de conocimiento, la cual comprende al sistema de las ciencias pero lo desborda, para incluir al campo intelectual en su conjunto y a una serie de instancias de producción, transferencia y difusión de conocimientos que alimentan esa mayor autonomía relativa de la sociedad civil.

- Las mediciones e indicadores nacidos de las ciencias sociales son una más de esas potentes tecnologías que mantienen a raya al Estado imponiéndole nuevas formas de gestión y accountability. Las prácticas evaluativas generan por su lado una fuerza performativa de poderosos efectos. Al punto que puede uno imaginar que impulsada por este movimiento -indicadores de desempeño, medición de resultados, fijación de estándares, ejercicios de benchmarking, informes de competitividad, cuantificaciones 
de todo tipo de capitales y motivaciones; en fin, cientificación y tecnificación de las formas de acción y control— está dibujándose una nueva cara del capitalismo. Aquella de la aceleración de los desempeños y las cuantificaciones de la productividad en todos los frentes y organizaciones de la sociedad: hospitales, universidades, editoriales, intimidad, alimentación, deportes, ciudad, arte, sexo, cuerpo, religiosidad. La manufactura taylorista, fordista y postfordista de los comportamientos proporciona la base de un universo productivista en los servicios, el hogar, la industria, las escuelas y universidades así como del panóptico neobenthamiano y las disciplinas foucaultianas. Por todas partes se difunde el imperativo ético de rendir al máximo e innovar y adoptar las mejores prácticas; imperativo válido para cualquier ámbito de la vida personal, familiar, comunitaria y organizacional, en la sociedad y el Estado. De ser así, es posible que el hombre (tal como lo conocemos) termine por desaparecer, igual como en los límites del mar un rostro de arena (Foucault, 1968: 378). Ciencias sociales: ¿podría ser ésta, al final, tu paradojal victoria?

\section{Competencia en el campo intelectual}

Es momento de volver a Bourdieu y a la explicación del estado actual y el rol performativo de las ciencias sociales. A propósito de la lectura de los textos que comentamos (Ariztía, 2012), surge la siguiente pregunta: ¿dónde cabe poner el acento del análisis: en los productores o en los usuarios; en el polo de la oferta de conocimiento o de la demanda y el consumo; o en un punto intermedio, justamente, el de los intermediarios? En gran medida, el análisis bourdiano de campos o espacios sociales posicionalmente estructurados, como el campo intelectual y el de las ciencia sociales, lleva a pensar que lo importante son las propiedades del campo; las posiciones ocupadas por los productores y sus estrategias. Estas últimas pueden ser de conservación de poder, de sucesión o de substitución por grupos emergentes, pertenecientes a nuevas generaciones, escuelas de pensamiento o estilos de acción.

La mayoría de estos textos adopta, gruesamente, ese enfoque. Hablan de intelectuales, sociólogos públicos, tecnócratas, technopols, académicos, investigadores, posiciones universitarias e instituciones de 
conocimiento. En suma, productores (e intermediarios en algunos casos) del campo de las ciencias sociales y sus estrategias de poder y uso de las ciencias sociales.

A diferencia de los análisis de Bourdieu, sin embargo, los autores no se aventuran en el estudio de las dinámicas de campos, entendidos éstos como arenas de lucha por la legitimación de los recursos considerados más valiosos dentro de cada espacio. Por eso mismo, el carácter antagonístico, agónico a ratos, de los análisis bourdianos aparece apenas insinuado aquí y allá; los productores e intermediarios, por el contrario, se presentan como grupos relativamente unificados y sin fricciones dentro de su arena. No ocurren así las cosas en la práctica, sin embargo. Al contrario, en los campos bourdianos los agentes - sean individuos o instituciones- ocupan posiciones dominantes y dominadas dentro de ese espacio; son incumbentes de posiciones o contendientes que buscan acceder a ellas; se comportan por lo mismo estratégicamente en función de sus intereses posicionales. Compiten por visibilidad, reputación y recursos. Efectivamente, el principal vector de esta dinámica es la competencia por mantener y ampliar los distintos tipos de capital en disputa dentro de un campo. Y, en el caso del campo intelectual, el poder simbólico, consistente en la capacidad de nombrar legítimamente, de designar fenómenos, imponer clasificaciones, crear categorías y aprovechar para sí el efecto performativo de las ciencias sociales.

La acumulación de capital simbólico otorga prestigio, el cual sirve, a su vez, en la competencia por ocupar posiciones dominantes dentro del campo. Dice por ahí Bourdieu: "existir es diferir; es decir, ocupar una posición distinta, distintiva". Y en otra parte habla de una "ley de la búsqueda de distinción", tema al que luego destinaría un volumen completo. Más inquietante aun, sostiene que "la toma de posiciones intelectuales, artísticas o científicas es resultado, siempre, de estrategias inconscientes o semiconscientes en un juego donde se lucha [también] por la conquista de legitimación cultural o, dicho en otros términos, por el monopolio de la legítima producción, reproducción y manipulación de bienes simbólicos y su correspondiente poder de legitimación"

Con todo, el análisis de los usos de las ciencias sociales necesita ir más allá del trabajo y la lucha de productores dentro de un campo; supone la continua interacción de aquéllos con intermediarios y usua-

${ }^{4}$ Citado en Swartz (1997:228, nota 21). 
rios o consumidores del conocimiento producido. Es decir, el campo tiene que expandirse para incluir los distintos mercados en que los intelectuales y científicos sociales invierten. Esta perspectiva ha sido utilizada asimismo por Bourdieu al distinguir entre académicos cuya producción se halla orientada hacia los pares y el sistema académico para su reproducción —o sea, mercados altamente especializadospor un lado y, por el otro, académicos orientados hacia audiencias masivas, no especializadas, situados en espacios más propensos a la comercialización y donde los enunciados discursivos se sujetan a criterios externos al campo académico. En un caso se busca el reconocimiento de pares y la influencia propia de las ciencias; en el otro, salir al encuentro de la demanda de públicos situados al exterior del campo. Bourdieu elabora una serie de interesantes análisis en línea con este tipo de distinciones, como ocurre en su principal estudio dedicado a los académicos (Bourdieu, 2008). Por ejemplo, muestra allí que en el mundo universitario francés existe una nítida separación entre facultades, escuelas, departamentos, profesores y estudiantes que se hallan más próximos al polo del capital económico, como en el caso de medicina y leyes, y aquellas unidades y componentes más próximos al polo del capital cultural, como las ciencias naturales y sociales, las artes y humanidades. Al interior de estas últimas estudia luego varias formas distintivas de poder. En primer lugar, el que detentan quienes controlan los mecanismos institucionales de reclutamiento, carrera y promoción del personal junto a recursos de investigación y designaciones honoríficas (la alta burocracia universitaria, a la que pertenece el homo academicus). Luego, en segundo lugar, el poder que poseen los científicos reconocidos por sus pares que consiguen reputación académica, los cuales a su turno se diferencian entre aquellos que compiten esencialmente por prestigio disciplinario (campo científico) y aquellos que buscan trascender los límites del campo e incidir a través de su producción sobre públicos (educados) más amplios (campo intelectual). Finalmente, en tercer lugar, menciona a los "mandarines" — conocidos en el sistema Oxbridge como dons y a quienes Burton Clark da el nombre de "oligarquía académica"-, los cuales reúnen los tres tipos anteriores de poder: científico, intelectual y burocrático-académico. Son reconocidos por sus pares a través del sistema de citas; por públicos más amplios y menos especializados por su influencia intelectual y, además, ocupan 
posiciones institucionales clave para el control de los flujos de ideas, personas, carreras, recursos, cargos y prestigios dentro del sistema académico.

\section{Innovaciones en el campo de las ciencias sociales}

Varias de estas distinciones, categorías y conceptos aparecen sugeridos también o están latentes en los estudios del volumen editado por Ariztía (2012). En cualquier caso, su interés reside no en su proximidad con el análisis bourdiano de campos sino en su deseo de explorar nuevas direcciones e innovar en el campo de la sociología de las ciencias sociales chilenas. Comentaré a continuación brevemente tres de esas innovaciones que, a mi juicio, podrían llegar a constituir líneas de diferenciación (¡aquí donde diferenciarse es regla y distinguirse es existir!).

\section{Intelectuales entonces y ahora}

Sin duda los análisis actuales de la intelectualidad son distintos de los que realizamos algunos investigadores sociales chilenos durante los años 70, 80 y 90 del siglo pasado (Brunner, 1990, 1989; Brunner y Sunkel, 1993; Brunner y Flisfisch, 1983). En efecto, la idea misma del intelectual y de los académicos públicos del campo de las ciencias sociales se hallaba referida entonces más a la sociedad - y a las clases y grupos en pugna dentro de ella- que a un campo específico de agentes e instituciones especializadas como uno ve emerger ahora en los textos que comentamos. La idea gramsciana del intelectual orgánico encontraba justamente en el referente anterior su más poderoso apoyo. Lo que interesaba a mi generación, creo yo, era sobre todo la relación del científico social como intelectual público con la política, el poder y su expresión weberiana en el Estado.

Efectivamente, la sociología pública de nuestra generación, como bien señala uno de los artículos incluidos en este volumen (Ariztía y Bernasconi, 2012), asumía una suerte de compromiso con grandes temas: modernidad, democracia, transformaciones del capitalismo, cambio del régimen político. Y pretendía, enseguida, pronunciarse respecto de cualquier tópico de la coyuntura, línea en la cual nos sentíamos secretamente cómplices con la figura del "intelectual total" que en 
los años 60 habíamos aprendido a admirar en Sartre. De allí asimismo la noción subyacente del intelectual-sociólogo-militante que se expresaba a través del compromiso orgánico con fuerzas políticas; compromiso que venía impuesto no solamente como reacción frente a la dictadura sino que tenía, además, un sustrato en la ideología del académico-intelectual que habíamos comenzado a cultivar en la universidad durante los años 60. (Por lo mismo, es probable que este cambio de enfoque tenga que ver con la lenta autonomización (relativa) del campo intelectual y académico respecto de la política y los partidos ocurrida durante la última década. Es al menos una hipótesis que convendría explorar.)

En paralelo cabe considerar que, con el surgimiento de un capitalismo más intensivo en conocimiento científico-técnico, se multiplican también las figuras que en sentido lato pueden clasificarse de intelectuales: ya no solo "funcionarios de lo universal", como alguna vez se los definió sino, además, tecnócratas, analistas simbólicos, technopols, intelectuales específicos, especialistas en orientación cultural, sociólogos públicos, ciertas categorías de literatos y periodistas, todos miembros de unas elites que se valen de su capital cultural para disputar posiciones, labrar sus trayectorias y ser reconocidos en campos especializados de poder simbólico.

En estas circunstancias desaparece la idea de un intelectual orgánico ligado por múltiples vínculos a las fuerzas históricas de cambio y conservación para dar paso a una noción de redes especializadas que, entre otras cosas, buscan profundizar la autonomía relativa de sus respectivos campos intelectuales, en línea con lo anticipado por Bourdieu. Ha desaparecido Sartre como modelo - junto con figuras como Aron, Tourain, Morin, Dahrendorf o Chomsky y, en América Latina, Fernando Henrique Cardoso, Pablo González Casanova, Gino Germani, Norbert Lechner o, en un campo vecino de la literatura y el ensayo, Octavio Paz, Carlos Fuentes y Mario Vargas Llosa- y surgen modelos como el del intelectual específico, anticipado y favorecido por Foucault (1992:78-88); o del tipo profesionales de la sociología pública promovida por Burawoy (2005) y discutida por Calhoun (2005); o especialistas de campos subdisciplinarios como sociólogos de la educación, o de las organizaciones, o del consumo, o bien cultivadores de diversas escuelas de pensamiento sociológico: crítico, deconstructivo, emancipatorio, feminista, neocolonial, neomarxista, etcétera.

La famosa fragmentación posmoderna - junto con el descentramiento, el fin de los grandes relatos, la implosión de los discursos, la 
hibridación y el advenimiento de una sociedad de flujos y fenómenos "líquidos" a la manera descrita por Zygmunt Bauman - se hacen cargo así de transformar también las bases de la sociología de los intelectuales y sus campos.

\section{Desplazamientos y nuevos objetos}

Asimismo, el desplazamiento desde el polo de la producción hacia el polo de los intermediarios y usuarios, públicos o consumidores forma parte del cambio de marea en dirección a un capitalismo de la circulación: desde las estructuras y fuerzas productivas a los mercados y la innovación; desde el ascetismo del trabajo a la medición de los resultados; desde la alta cultura a las culturas mesocráticas y de masas; desde la enunciación de contenidos controlada por el emisor hacia la circulación de los signos cuyo sentido sólo aparece en el acto de su recepción y elaboración por los usuarios finales.

De hecho, los estudios reunidos en Ariztía (2012) son tributarios también de esos desplazamientos. Como ya habíamos anticipado, el campo intelectual bourdiano - centrado en la producción y los productores, herencia compartida con estructuralistas y marxistas - ha ido transformándose con la literatura reciente en un complejo entramado de redes. Redes donde las posiciones son menos fijas; donde hay más intercambio que mera producción; donde el poder simbólico se intensifica en los nodos y donde tanto importan los agentes iniciadores de una comunicación — que en realidad nunca son tales, pues se hallan situados siempre dentro de una red de aprendizajes y citas, códigos y socializaciones, conceptos previos y prácticas de uso, inscribiéndose por tanto, intertextualmente, en una corriente que viene descendiendo con la historia - como aquellos que la prosiguen, desvían, interrumpen, sirviendo de interfases, y aquellos que la reciben, interpretan, reelaboran, traducen y prolongan en diversas direcciones. En esta perspectiva, la "producción de lo social" aparece como altamente dependiente de tales usos y éstos constituyen, a su vez, un campo de fuerzas que extiende y completa el campo de la producción mediante aparatos intermedios (por ejemplo, prensa, televisión, radio, internet, editores, editorialistas, docentes y transmisores de conocimiento, comentadores, analistas, periodistas, intérpretes de encuestas, 
publicistas, ensayistas, etcétera); redes de comunicación de diversos tipos de saberes; instituciones que operan como correas generadoras, transportadoras y distribuidoras de conocimiento tales como escuelas, universidades, seminarios, talleres, encuentros profesionales, circuitos internacionales, librerías y bibliotecas (especialmente virtuales), sitios especializados de la red en diversas operaciones de intermediación, búsqueda, arbitraje, contextualización y transformación de conocimientos; $\mathrm{y}$, por último, mediante receptores distribuidos entre variados tipos de agencias: individuales, grupales y colectivas; audiencias segmentadas por estatus socioeconómico, género, identidades, edad y tecnologías de recepción; públicos con diversos grados de especialización, interés, atención; sujetos virtuales construidos por las encuestas y otras técnicas de auscultamiento y control; usuarios más o menos comprometidos con la comunicación, poseedores de distintos tipos y volúmenes de capital cultural, y con trayectorias y experiencias de vida diversas.

Estas heterogéneas configuraciones, en permanente cambio, aparecen ahora como el objeto de la nueva sociología del campo de las ciencias sociales. Al mismo tiempo permiten renovar el análisis de las relaciones entre elites y masa por ejemplo, donde ya no es posible abstraerse de las múltiples mediaciones que existen entre el campo de producción - con sus posiciones dominantes y dominadas y sus luchas por el control de las posiciones favorecidas-y el campo de la recepción con sus múltiples procesos de antena, sintonía, lectura, hermenéutica, descodificación, recodificación, uso y transmisión. Y, en medio de ambos polos, como acabamos de ver, toda una compleja trama de intermediarios humanos, tecnológicos, de relaciones sociales, operaciones, circuitos y aparatos.

\section{Credenciales: estatus y valor de cambio}

Finalmente, no escapa a nadie que las agencias de estos campos de producción-intermediación-recepción a través de los cuales se construye y disputa el poder simbólico, son personas (o se hallan operadas por personas) con credenciales educacionales superiores, cada vez más ampliamente distribuidas pero, al mismo tiempo, jerárquicamente ordenadas. Los productores de conocimiento avanzado, de productos y servicios intelectuales, científicos sociales, expertos, así como los intermediarios técnico-burocráticos y culturales, comunicadores, docentes- 
transmisores eruditos, y los receptores-usuarios activos, ilustrados y reproductores prácticos, forman parte en su conjunto del personal letrado. Han sido educados en el nivel terciario; cuentan por tanto con grados académicos o diplomas profesionales o técnicos. Son consumidores de bienes culturales sofisticados y, su segmento más elevado, productores de conocimiento o activos participantes en la circulación de signos, en las más distintas áreas del saber y la cultura. Su posición en los campos académico, intelectual y científico, al igual que en los mercados relevantes, se señaliza por la posesión de certificados educacionales que dan cuenta de su "capital humano" y su rol en los circuitos del poder simbólico.

Las mujeres y hombres acreditados por una institución selectiva de estudios superiores en posesión de diplomas prestigiosos (signo de honor y estatus pero dotado también de valor de cambio en el mercado ocupacional) pasan a formar parte de los diferentes estratos detentadores de capital cultural: la nobleza de Estado como la llama Bourdieu (1996) en el caso de los graduados de las grandes escuelas francesas; nuestros tecnócratas, tecno-burócratas y technopols; los estamentos profesionales que, desde Weber, sabemos son portadores de un estatus especial; toda la amplia gama de intermediarios intelectuales, partiendo por los docentes universitarios; los científicos en diversas ramas del saber, sea que se inclinen más hacia el modelo del académico disciplinario a la manera de los investigadores con su identidad cosmopolita y su involucramiento en la creación de conocimiento; o al modelo del académico intelectual público que aspira a trascender el círculo de sus pares para dirigirse a audiencias no especializadas; o al modelo del homo academicus que valora sobre todo el control de las palancas burocráticas al interior de su institución.

Si la universidad se ha vuelto una institución estratégica en la sociedad contemporánea (antes lo era únicamente para las elites del campo cultural) es porque opera como dispensadora de credenciales para las amplias capas de la sociedad llamadas a participar en estos campos ampliados o extendidos del conocimiento, sea como productores, intermediarios o receptores. Gatekeeper institution dice la literatura anglosajona (Pappas y Tremblay, 2010); esto es, aquella que cuida las puertas de acceso a estos campos donde se disputa el poder simbólico y se resuelve el dominio en las sociedades que usan intensivamente el conocimiento. 


\section{REFERENCIAS}

Ariztía, T. (ed.) (2012). Produciendo lo social. Usos de las ciencias sociales en el Chile reciente. Santiago: Ediciones Universidad Diego Portales.

Ariztía, T. y O. Bernasconi (2012). "Sociologías públicas y la producción del cambio social en el Chile de los noventa". En T. Ariztía (ed.), Produciendo lo social. Usos de las ciencias sociales en el Chile reciente. Santiago: Ediciones Universidad Diego Portales, 133-163.

Bordieu, P. (2008). Homo Academicus. Buenos Aires: Siglo XXI.

(2000). Intelectuales, politica y poder. Buenos Aires: Eudeba.

(1996). The State Nobility. Stanford, California: Stanford University Press.

Bourdieu, P. y L. Wacquant (2008). Una invitación a la sociología reflexiva. Buenos Aires: Siglo Veintiuno Editores.

Brunner, J.J. (1990). "Los intelectuales y la democracia". En A. M. Stuven (ed.), Democracia contemporánea, transición y consolidación. Santiago: Ediciones Universidad Católica de Chile, 71-92. - (1989). "Los intelectuales y los problemas de la cultura del desarrollo". Santiago: FLACSO, Material de Discusión, 117.

Brunner, J.J. y G. Sunkel (1993). Conocimiento, sociedad y política. Santiago: FLACSO.

Brunner, J.J. y A. Flisfisch (1983). Los intelectuales y las instituciones de la cultura. Santiago: FLACSO.

Burawoy, M. (2005). "For Public Sociology". American Sociological Review, 70, 4-28.

Butler, J. (1993). Bodies that Matter: On the Discursive Limits of 'Sex'. New York: Routledge.

- (1990). "Performative Acts and Gender Constitution: An Essay in Phenomenology and Feminist Theory". En S. E. Case (ed.), Performing Feminisms: Feminist Critical Theory and Theatre. Baltimore: Johns Hopkins UP.

Calhoun, C. (2005). "The Promise of Public Sociology". The British Journal of Sociology, 56(3):355-363.

Foucault, M. (1992). Microfísica del poder. Madrid: La Piqueta. (1968). Las palabras y las cosas. Buenos Aires: Siglo Veintiuno Editores Argentina.

Pappas, G. y C.W. Tremblay (2010). "Meritocracy: The Great American Myth? A Look at Gatekeeping in Higher Education". College \& University Journal, 86:28-34.

Perkins, H. (1990). The Rise of Professional Society. London: Routledge.

Swartz, D. (1997). Culture \& Power. The Sociology of Pierre Bourdieu. Chicago and London: The University of Chicago Press.

Turner, S.P. (2003). Liberal Democracy 3.0. Civil Society in the Age of Experts. London: Sage Publications.

Thompson, J. B. (2001). El escándalo político. Poder y visibilidad en la era de los medios de comunicación. Barcelona: Paidós. 